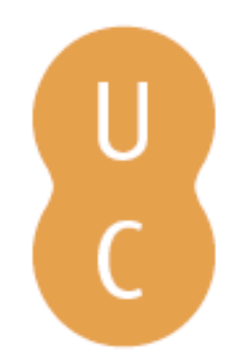

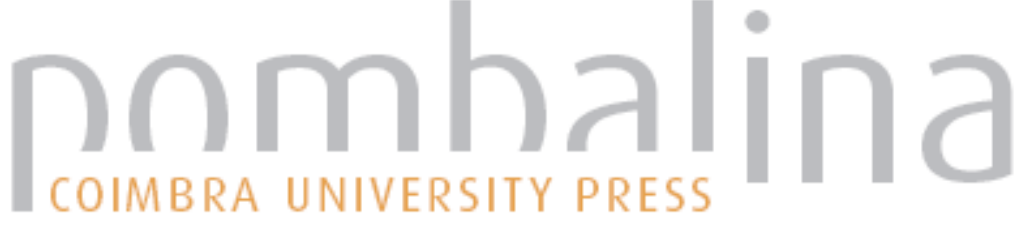

\section{Elderly \& ICT: a need and urgency for an effective info-inclusion}

Autor(es): $\quad$ Gil, Henrique Teixeira

Publicado por: Imprensa da Universidade de Coimbra

URL

persistente:

URI:http://hdl.handle.net/10316.2/32509

DOI:

DOI:http://dx.doi.org/10.14195/978-989-26-0732-0_11

Accessed : $\quad$ 26-Apr-2023 09:50:59

A navegação consulta e descarregamento dos títulos inseridos nas Bibliotecas Digitais UC Digitalis, UC Pombalina e UC Impactum, pressupõem a aceitação plena e sem reservas dos Termos e Condições de Uso destas Bibliotecas Digitais, disponíveis em https://digitalis.uc.pt/pt-pt/termos.

Conforme exposto nos referidos Termos e Condições de Uso, o descarregamento de títulos de acesso restrito requer uma licença válida de autorização devendo o utilizador aceder ao(s) documento(s) a partir de um endereço de IP da instituição detentora da supramencionada licença.

Ao utilizador é apenas permitido o descarregamento para uso pessoal, pelo que o emprego do(s) título(s) descarregado(s) para outro fim, designadamente comercial, carece de autorização do respetivo autor ou editor da obra.

Na medida em que todas as obras da UC Digitalis se encontram protegidas pelo Código do Direito de Autor e Direitos Conexos e demais legislação aplicável, toda a cópia, parcial ou total, deste documento, nos casos em que é legalmente admitida, deverá conter ou fazer-se acompanhar por este aviso.

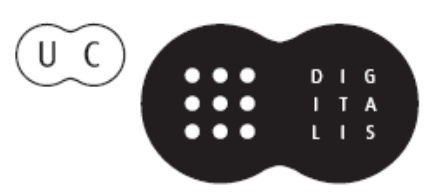


MPRENSA DA

UNIVERSIDADE

DE COIMBRA

COIMBRA

UNIVERSITY

- PRESS 


\title{
ELDERLY \& ICT: A NEED AND URGENCY FOR AN EFFECTIVE INFO-INCLUSION
}

\author{
Henrique Teixeira Gil ${ }^{31}$
}

\begin{abstract}
It is a fact that the world is aging and the developed countries are the most affected by this reality. In consequence, the majority of the population comprehends elderly people. The present knowledge society is characterized by technologies, digital devices and by the so called ICT (Information and Communication Technologies) and most present-day activities uses those devices. Recently, several expressions and services have introduced the ' $e$ ' and it is common to talk about $e$-commerce, $e$-learning, $e$-banking, $e$-government, $e$-Health... it means that citizens must be digitally literate to deal with and use those services as a routine of their everyday life. However there are a large number of people who have not the necessary digital skills and consequently they become info-excluded. The group of the info-excluded is represented by women, people with a low level of literacy, the unemployed, and the elderly. Being sure that the elderly will constitute in the future (and in the present) the greater percentage of the citizens it is urgent to promote initiatives in order to train those citizens in ICT. The European Union already felt that need and therefore several action plans were launched (e.g. The Riga Declaration; $i 2010$ e-Inclusion Initiative). It is consensual that ICT will promote a better quality of life so the elderly will benefit from it in order to promote an adequate active aging. It is the aim of this article to discuss the main initiatives carried on and present the main obstacles, advantages, and some clues for the near future for the use of ICT by elderly people.
\end{abstract}

Keywords: Elderly; ICT; Info-inclusion; Info-exclusion.

\footnotetext{
${ }^{31}$ Instituto Politécnico de Castelo Branco - Escola Superior de Educação

Email: hteixeiragil@ipcb.pt
} 


\section{An aging society: Perspectives for the future}

The world is experiencing an important demographic transformation due to the unprecedented aging of the population of almost all developed and developing countries. The increasing presence of older people in society makes people of all ages more aware that they are living in a multi-generational society. Increasingly, aging populations may influence global patterns in almost all services, labour, capital markets, and traditional social support systems like health care and pensions mainly in European countries. In all the Member States of the European Union (EU) the current fertility rates are low and if birth rates continue to decrease as predicted, the proportion of young and old citizens will undergo a historic crossover. A moderate projection of aging in the EU for the period between 2004 and 2050 shows that the population aged $65+$ will increase by 58 million or $77 \%$ and that, at the same time, the working-age population will drop by 48 million or $16 \%$. In the EU, this might mean that the ratio of people of working age would be two for every older citizen, instead of four working people at the present time (European Commission, 2007).

The next figure (23 and 24) show this tendency and put in evidence the aging of the society in all over the world. It may be observed that the European Union and the most developed countries present the highest percentage of elderly people as was stated above:

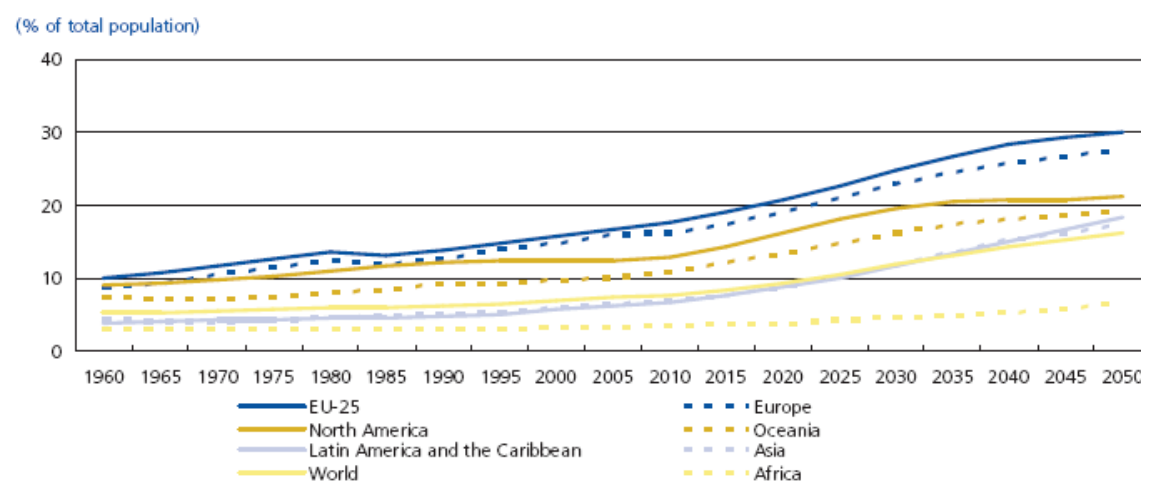

Figure 23: Proportion of the population aged 65 and over in selected world regions (Source: Eurostat 2007) 
Figure 24 highlights the old-age dependency ratio in selected world regions:

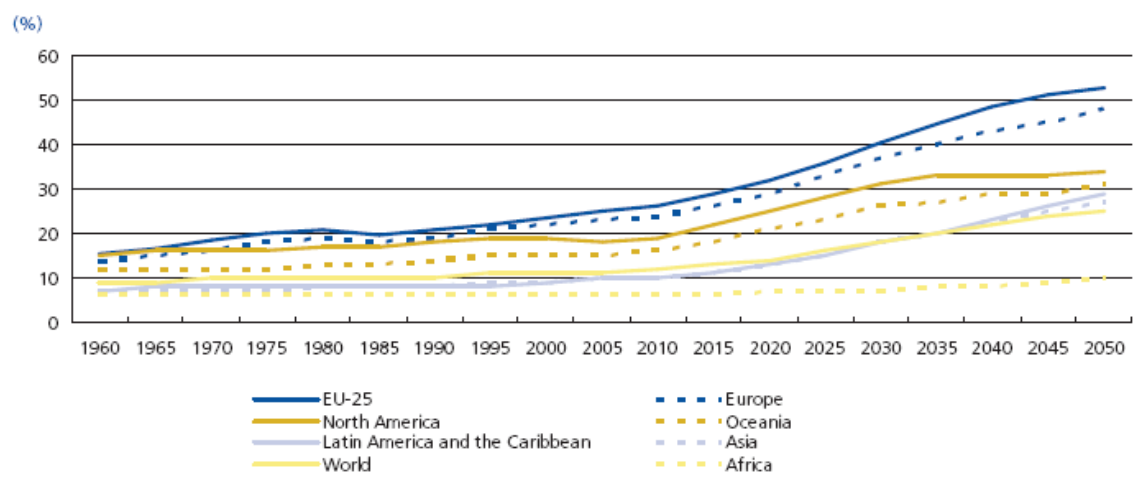

Figure 24: Old-age dependency ratio in selected world regions (Source: Eurostat 2007)

Aging will be the dominant and most visible aspect of world population dynamics in the 21st century according to the trend that was explicit in Graphs 14 and 15. It is expected that, by the year 2050, the populations of numerous countries, mainly the developed countries, will consist of over 30\% older persons. This situation presents both challenges and opportunities but the recommendations and policy advice must be interpreted for each national circumstance, to develop the most appropriate response to their own particular social and cultural situation. Chief among the recommendations are to promote the participation of older persons as citizens with full rights, and to assure that persons everywhere are able to age with security and dignity. Governments reaffirmed that the promotion and protection of all human rights and fundamental freedoms, including the right to development, are essential for creating an inclusive society for all ages (UN, 2008).

Based on the basic pillars of the WHO (2002) concept on Active Ageing, it is recommended that specific higher level needs of elderly people with regard to quality of life in highly developed countries be classified into five main groups:

a) Health: non-existence of illness, a good functional status and an appropriate system of social support for the individual; the decision as 
to whether one is healthy or ill depends strongly on one's perception of one's own body; it is assumed that in coming years, it is expected that better informed patients will take on more responsibility for their own health; it is also expected that elderly people will be more proactive when asking for a medical diagnosis, medical treatment and medical therapy.

b) Safety: personal safety is very important both in everyday life and at home; the most common challenges are physical infirmity and the loss of mental abilities and cognitive performances of which the restrictions quite often lead elderly people to make the necessary adjustments and use safety products (e.g. assistive technologies); other cases with more serious restrictions may lead to admission to an institution which means a very serious loss of individual autonomy by the elderly.

c) Independence: elderly people like to live an independent and autonomous life as long as possible and a central point is living independently in their own homes; usually moving to an institution is regarded as something negative, however, for elderly people who have an increasing number of serious handicaps, it is much more difficult to continue independent living.

d) Mobility: there is a strong need among elderly for mobility; however, the aging process usually promotes a reduced mobility; in consequence, a serious reduction of mobility can lead to enormous reductions in quality of life of elderly people.

e) Participation: being part of everyday life is one of the central needs of elderly people; social contact and relations with other people have a positive influence on well being and health in older age; an increasing number of elderly people decide, for instance, to learn more about new topics and attend courses at universities and other educational institutions and this is part of their quality of life (Malanowski, Özcivelek \& Cabrera, 2008).

If there is a need and an urgency to invert the present situation, ICT contributes to improving the quality of everyday life and social participation of Europeans, facilitating access to information, media, content 
and services, to enhanced and more flexible job opportunities, and to fight against discrimination. Improving ICT access for people with disabilities and the elderly is particularly important (European Commission, 2007). Many Europeans still reap few or no benefits from ICT and there are resilient gaps in ICT use. For instance, $57 \%$ of individuals living in the EU did not regularly use the Internet in 2005; only $10 \%$ of persons over 65 used the Internet, against $68 \%$ of those aged 16-24; only $24 \%$ of persons with low education used the Internet, against $73 \%$ of those with high education; only $32 \%$ of unemployed persons used the Internet against $54 \%$ of employed persons. Figure 25 shows the individual use of the internet and/or computers among the European Union members that allows us to identify the main group of the info-excluded: unemployed, citizens with lower education and, the most elderly (retired included):

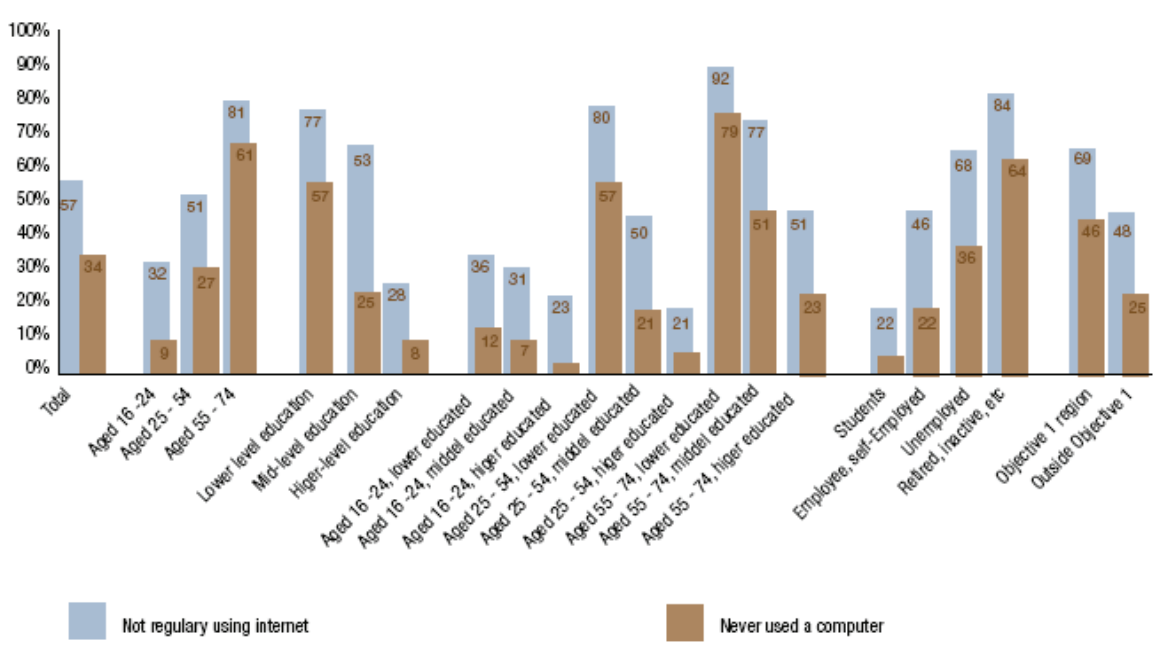

Figure 25: Individuals using the Internet and/or Computers (EU 25, 2005).

The Ministerial Declaration of Riga (2006) was approved not only by the EU 27 but also by the EFTA and several countries that joined the Meeting in order to settle some basis for a global strategy to promote "eInclusion". According to the Riga Ministerial Declaration ICT is so powerful that it can promote a growth of productivity around 50\% and they also believe that ICT contributes to improving the quality of everyday life and the 
social participation of the European citizens. The conjunction of the aims approved on behalf of the Ministerial Riga Declaration (2006) was coherent with the «i2010 $e$-Inclusion Initiative» that was launched one year later by the European Commission (2007), the main aims to achieve being:

a) Exploiting the full potential of the internal market of ICT services and products for the elderly, amongst others by addressing demand fragmentation by promoting interoperability through standards and common specifications where appropriate; barriers to innovative ICT solutions for social security and health reimbursement schemes need to be addressed, particularly at the national level.

b) Improving the employability, working conditions and work-life balance of older workers to improve productivity by supporting innovative ICT solutions which can be easily used everywhere including at home, and encouraging the provision of training from the public, private sectors and from civil society, making special efforts on ICT skills for elderly people.

c) Enhancing active participation in society and economy and self-expression, through innovative ICT-enabled access to goods and services, and relevant content, to facilitate interactions with public and private entities, entertainment, and social contacts.

d) Realizing increased quality of life, autonomy and safety, while respecting privacy and ethical requirements; these aims can be achieved through independent living initiatives, the promotion of assistive technologies, and ICT-enabled services for integrated social and healthcare, including personal emergency and location-based services.

\section{'Info-exclusion vs. Info-inclusion': Main reasons, main barriers and main constraints}

In the 'developed' parts of the world we live in aging societies in which technology is of increasing importance in everyday life. Given this conjunction, it becomes ever more important to examine the ways in which 
technology serves the elderly population. There is a need not only to focus on the detail of usable interfaces for elderly people, but also to examine the wider implications of the introduction of technology into their lives. Concerns among gerontologists that technology is growing faster than its implications can be understood must be taken seriously (Dickinson \& Gregor, 2006). The requirement to learn to use new technologies is becoming pervasive in the lives of adults, young and old. For example, computer systems of various forms are prevalent in nearly every aspect of our lives, including video-cassette recorders, computerised library catalogues, electronic banking, information kiosks, multi-function answering machines ad infinitum (Selwyn, 2004).

ICT can support learning in many ways, allowing more individual learning approaches; compensating for disabilities; and providing new opportunities to access information and services as well as to interact with other people and communities. However, it may also bring new obstacles. ICT are new for many older people today and the threshold for taking up new tools and applications to begin new learning activities may be high. Attention should be paid to improving the usability of tools; access to the equipment; and to the types of learning opportunities provided. As the background and motivation of elderly people may differ from those of the other elderly people, as well as from younger generations, special considerations are needed to design ICT-supported learning approaches that can provide relevant learning for all participants (Purdie \& BoultonLewis, 2003). Concerning the older people of tomorrow ('baby boomers') some authors see tremendous exposure to computer applications which will lead to a growing openness and increasing competency with respect to using technological innovations. However, they do not expect that all elderly people in this group will be able to take advantage of these technological advances ('digital divide') since their experiences with future technology, their educational backgrounds and their incomes may vary significantly. As argued by Malanowski, Özcivelek and Cabrera (2008), they predict a number of elderly nonusers of ICT in the near future who will be at risk of being excluded from important social domains. For elderly adults who are not comfortable with IT, feelings of exclusion may 
increase. They then would seem less likely to recognize the potential for the technology in their own lives. Because of the rapidity with which IT is changing and progressing, this problem is unlikely to diminish (White \& Weatherall, 2000). The conceptualization of a technological divide is based on notions that social inequities exist in relation to the use and optimization of ICT. In the opinion of West and Heath (2009), these inequities manifest themselves in various forms both locally and globally. Particularly in recent decades social researchers have questioned technological inequity and attempted to establish theoretical frameworks to enhance understandings of human use of ICT, factors which influence this use and the consequences of not using technology. Digital exclusion comes in many forms but can broadly be described in this context as comparative or relative limitations in any combination of technological access, knowledge, awareness, learning opportunities, support and/or skills. According to the ICT4T (2006) the digital divides are determined not only by age, but also by gender aspects, educational backgrounds and income levels and also geographical locations. The research revealed that even though home computer availability declined with age, part of this relationship was due to the effects of such factors as employment status, marital status, race, gender, family income, living arrangements, education, and number of disabilities. Interestingly, use also declined with age among persons who owned a computer, irrespective of socio-demographic differences. In the opinion of Blit-Cohen and Litwin (2005), the analysis concluded that age-related computer availability is influenced by socio-demographic factors, but that computer use indeed declines with age. Millar and Falk (2000) also noted that a lack of practice time is a barrier for some elderly adults who do not have computers and skills-learning support, resulting in a lack of confidence but they also suggest this is associated with limited literacy skills.

As argued by Barnett and Adkins (2004), research also indicates that there are complex issues related to elderly people's up take of computer technology. For instance, the costs of set up and access, lack of computer and Internet literacy, and physical difficulties that are associated with the use of many electronic services are one set of factors. Elderly users 
may also have either a favourable or negative response to the design and operational features of computers. Typically, technology researchers and developers are young, and do not fully appreciate the needs of elderly users. According to Morgan (2005) it is generally believed by those involved in manufacturing new computer equipment that elderly adults, because they often have fewer financial resources or have older children with computers, will hold back on purchasing new computer equipment and software or acquiring basic training. As a result, there are very few companies who see a market in developing computers that are user-friendly for older adults.

For elderly learners the new developments mean the need to acquire media literacy, the basic know-how of using the new technical tools for information, communication and exchange, but also digital literacy, which means the possession of knowledge on how to evaluate information for accuracy and value to personal needs and how to integrate and to apply the accessed information with an awareness of ethical, social and economic issues. The development of target-group-oriented courses and other education activities to familiarise the elderly people with the use of the ICT or education activities which use the ICT as tools is complex due to the diversity within the age groups in terms of interests, capabilities, physical fitness, life situations, motivation to learn, etc. and to changing age perceptions and focus (ICT4T, 2006). In the opinion of Timmermann (1998), the seemingly obvious way for elderly people to learn how to use a computer is to enrol in computer classes with people of all ages. But this is far from an ideal situation because most computer classes are designed for job-related training. Research in adult learning theory and practice indicates that reaction time slows as people age, and more time is needed to learn by rote and to process information. We also know that elderly adults learn well in a learning environment that allows for self-paced instruction; this principle is especially applicable for those who must learn to use unfamiliar high-tech equipment. There are also some attitudinal barriers that need to be overcome; many elderly adults are uneasy about trying their hand at a computer, and need an opportunity to build their confidence and self-esteem. However, 
as argued by Timmermann (1998), many elderly people believe they are 'too old' to learn the computer. This attitude stems, in many ways, from unfamiliarity with and anxiety about new technology. The fear of hitting the wrong key and then being unable to make corrections, or even breaking the computer, can be paralyzing for people of all ages, and particularly elderly adults. Embarrassment is another emotional barrier. Many older men, particularly those in management or the professions, relied on their female secretaries to type their correspondence; they never had experience with a keyboard and never felt it was appropriate to learn. Learning keyboarding as well as the technology from fast-paced instructors in a class full of young adults is a humbling and, for some, a threatening experience. In this context, Barnett and Adkins (2004), suggests that age-related impairments such as vision, hearing and memory loss, and loss of mobility, contribute to loss of confidence and difficulties in orientation and absorption of information. Timmermann (1998) also stressed that remembering the operating instructions such as turning on the computer, using the mouse, naming and saving files and printing documents can prove to be difficult for some elderly adults. Elderly people may experience some short term memory loss and, coupled with computer anxiety, may have a difficult time remembering the seemingly illogical steps required to operate the computer.

Computer technology allows people of all ages to engage in a wide range of undertakings, such as playing computer games for pleasure, word processing, conducting information searches, sending e-mails and participating in multi-user chats on the Internet. Moreover, computer-based communication allows people to freely disseminate their own ideas, to acquire new social ties and to even establish new identities Morgan (2005). However, the use of computers requires access to and knowledge of computer technology. As a result, many elderly people today are unable to participate in computer-based activity. The entry of computers as a component of social engagement took place after many members of the current older cohort had already retired from employment. In addition, elderly people who remain actively employed often do not engage in computer-generated tasks as part of their work. Consequently, access to 
computer technology among the older generation is still limited (Blit-Cohen \& Litwin, 2005). As argued by Hazzlewood (2001), barriers faced by elderly and younger adults accessing information and communication technology are not only those blocking physical access to computers and connection to the Internet, but also to appropriate and timely availability of training and support matching the special needs of older adults. According to the viewpoint of ICT4T (2006), 'offliners' who are distanced from the Internet, who refuse it or who are not interested in it, do not believe that the web is a great invention. They do not see the benefits or its attractiveness. There are nearly no impulses for access or growth resulting from the new technological possibilities. Social pressure or the feeling of being isolated is the main reasons to get access. Those who plan to get access or those who are already experienced see barriers like costs, technological knowledge or handling of the data volume.

\section{Info-inclusion: The main advantages for 'the next step'}

The field of gerotechnology frequently refers to the digital divide, most often meaning the divide between elderly adults and the younger population as computer users. However, the uniqueness of technology, and particularly the application of technology for information and communication, is that it provides a bridge for people of all social and economic backgrounds to access parts of the world they might not have ever known existed. Thus by opening up these new opportunities, technology plays a significant role in society by helping to equalize the opportunities for personal growth and decision making throughout the life span, including opportunities for seniors who are limited in their activities of daily living (Morgan, 2005). When technology is made available to elderly adults it is a way of changing how they relate to themselves, their families, and society and how their families and society can relate to them. As a mechanism of social change, both computer-based technology and assistive technology are unique instruments that produce important social benefits. Although some have claimed that computer-based technology may diminish social 
isolation, there are others who see just the opposite - how this technology enables individuals to renew or develop new relationships with their family and establish a new circle of friends with common interests. Such networks can be made in their community, as well as globally. This empowerment of individuals to determine what they would like to do to enhance their lives is one of the key social impacts of this computer-based technology. 'Independent Living' has been one of the objectives of the many research programmes of the European Commission since 1990s. A technology initiative for disabled and elderly people - TIDE (pilot action in 1991) - aimed to stimulate the creation of a single market in assistive technology in Europe with a view to enabling elderly and disabled people to live more independent lives and become more integrated into the community. In the Fourth Framework Programme (1994-1998), one of the activity areas was 'Telematics' for improving employment and the quality of life. Equal access, independent living and participation for all in the Information Society were also part of the strategic objectives of Framework Programme 6 of European Commission (2007). In the opinion of Malanowski, Özcivelek and Cabrera (2008), central to independent living is the recognition that each individual has a right to the independence that comes from exercising control over his or her life, based on an ability and opportunity to make choices in everyday activities. These activities may include participating in community life; fulfilling social roles, employment, and citizenship; sustaining self-determination; and minimizing physical or psychological dependence on others. Independent living addresses the question of all citizens having an equal right to participate in society, and sharing the opportunities, risks, and rewards. The independent living philosophy promotes full participation of older people and also of people with disabilities in our society.

As argued by Bernard and Phillips (2000), technology is not something we can ignore in the new century, and we too would argue that technology should be at the heart of social policy for elderly people for several reasons:

a) First, it is intergenerational in the sense that technology has the ability to improve the situation and quality of life for all people. Each 
new generation in our society will be involved in creating new types of technology to improve the overall quality of peoples' lives. This in turn will place a 'technology lag' on the older generations who will need to learn how to adopt this technology into their lives. Perhaps one of the most positive social aspects of the current development of computer-based technology is that it has been an opportunity to build new relationships between the generations. Today, intergenerational learning is becoming much more accepted and developed as a way to increase learning capacity for both youth and older adults. This intergenerational approach also provides a better understanding of the strengths and needs of society in a much more purposeful and supportive manner (Morgan, 2005).

b) Secondly, technology is important to a social policy of aging because it pervades every aspect of life and has the potential for assisting with many of the 'traditional' problems associated with aging...

c) Thirdly, technology is pluralistic and preventative. It is about facilitating communication which can enable people, of whatever race, age or gender, to participate as citizens in decision-making and can empower people as they shop, vote and seek expert help 'on line' in all areas of policy. Technology can assist us to overcome some of the barriers already noted between conventional policy areas such as housing, health and social services, education and work, in order to create a 'seamless service'.

Technology will continue to move forward, and we do not know where it will venture next in helping improve our lives. However, as our society ages, we all have the opportunity to benefit from these new advances. This is the great challenge to us as researchers in the field of aging (Morgan, 2005). Exciting possibilities exist for new technologies to support elderly adults and their caretakers and to enable the maintenance of social contacts for those whose mobility is reduced. Technology developers must understand the special communication needs and the cognitive, affective, and sensory characteristics of older people and take these into account in developing technology for this population. Three major barriers impede communication with and for elderly adults: over 
accommodation to aging, word retrieval, and multitasking; each has implications for the design of communication technology for older adults. Technology has specific effects on work and especially on older workers, with significant differences in cohort responses to new technology. Technology can help elderly workers remain employed and maintain or upgrade their skills, as well as support the transition to retirement, through adaptive interfaces and other means of supporting computer input and output, software to provide planning and cueing assistance, and health monitoring devices.

In sum, these intergenerational relationships not only help individuals make better decisions for themselves and their communities, but also to become more sensitive to and participate in the understanding of national and global issues as concerned members of a civil society. Underneath this social change process, computer-based technology has been and will continue to be the driving force (Morgan, 2005).

\section{Lifelong learning \& ICT: Training elderly people for their info- -inclusion}

As a result of the lack of consumer involvement, some authors point out that, in their view, technology has diminished social interaction of older persons with service providers and perhaps with family members, as well. Moreover, it is suggested that technological determinism has frequently driven rather than responded to the needs of the consumer - in essence, making the consumer adapt to the technology (Morgan, 2005). One of the key research challenges in this field is getting elderly adults, family caregivers, and those intermediaries who work with them to understand that adoption of this new technology will help improve their lives, be cost effective, and will help increase personal control over their decision making. But this goal requires translating the new technology into potential benefits that are meaningful to the target population. Little research is currently directed to this agenda, particularly the value and cost-savings aspects. 
According to Barnett and Adkins (2004), the relationship between habitus and field in the context of older learners using computer technology can be understood as one of adaptation to the new in regard to interests, or dispositions. In this kind of learning relationship, the work of the peer tutor is important. In the first instance, the tutor has an understanding of the kinds of problems encountered by people in their later years. In a style highly reminiscent of the kinds of rote learning older people would have encountered in their school days, tutorials follow a similar logic. Repetition and practice is the basis of the teaching theory, maintaining the same format and reinforcing the terms and processes to use for various activities such as word processing, email and web browsing.

Knowledge society stands not only for knowledge and productivity, but also for the continual growth and update of knowledge. The term 'life-long learning' is often used in connection with vocational and continuing education. This applies also to elderly people. Especially in the area of vocational training is there a great need for training of older workers in order to keep them in employment. Although there is a large offer of this type of training in the area of eLearning, this is not focused on the needs of elderly workers (ICT4T, 2006). During recent years, the social and economic challenges that tend to be connected to these developments have received increasing policy attention, and the potential offered by ICT for better coping with them as well. Recently, the European Commission (2007) has adopted an Action Plan on Information and Communications Technology for Ageing in the framework of its $i 2010$ e-Inclusion Initiative. In this context, it is highlighted that better leveraging of the potential generally provided by ICT for independent living in an aging society represents both a social necessity and an economic opportunity. More specifically, it is emphasized that ICT holds considerable potential for more efficient management and delivery of health and social care, as well as increasing opportunities for community care and self-care and service innovation more generally. On the other hand, it has become evident that market forces alone have been insufficient to ensure the realization of this potential. As highlighted in this action plan, the market of ICT for aging well in the information society is still in its nascent phase, and 
does not yet fully ensure the availability and take-up of the necessary ICT-enabled solutions (European Commission, 2007).

As argued by Harper (2007), to create universal usability by designing for all involves making generalizations about users, and it is these exact generalizations that have led to so many users being excluded from the technological world in the first place. In practice, we suggest that universal usability is possible but not by using this 'design-for-all' ethos, in point of fact we suggest that it is only possible by 'design-for-one'. Once the opportunity is provided, interfaces can be developed to access that information in the most appropriate way to the user and not to the information itself. For instance, if an audio file is created without the opportunity of both a graphical or textual expression, then a hearing impaired user could not interact with that source. As stated by Chisnell and Redish (2004), younger users are more familiar with the language of the Web than elderly adults are. This becomes important as elderly adults encounter labels on navigation, buttons, fields, and links that use language that is unfamiliar to them and prevents them from inferring what the next content or step might be if that interaction widget is clicked. In order for older adults to benefit from advances that technology brings, but not be harmed by potential for technological failures, we must ensure that systems are designed with the capabilities and limitations of the older user in mind, provide proper training, and consider the needs of the elderly user in the development of future technologies. It is further pointed out that a central factor in abandonment of new assistive technology development is the lack of consumer involvement in the design and delivery process. This is particularly true for new technologies designed for older adults ranging from grab bars in bathtubs to computer-based automated medicine reminder systems.

Hazzlewood (2001) proposes that short courses tailored to meet the needs and interests of elderly people and avoiding information overload to ensure initial success are considered to be most effective in overcoming negative attitudes. Cases were also made for: formal small-group training to foster social interaction; individual instruction and support for oldest-old in residential care; and on-line learning for those isolated by distance 
or other circumstances. The ICT4T (2004) also refers that peer teaching models in which trained seniors take on the role of teachers have proved to be effective in teaching and guiding through the first encounters with the technical aspects of the new media. Peer trainers can understand and handle the initial fears and adjust better to the elderly people's learning pace. Barnett \& Adkins also agree that the use of peer teachers is fundamentally important because they have an understanding of the kinds of problems likely to be encountered by older learners - unfamiliarity with technology, memory loss, and tentative confidence levels.

A proposal for the design of a training course for elderly people may include the following categories according to the opinions that were collected and presented from Hazzlewood (2001), Chisnell and Redish (2004), ICT4T (2004) and, Harper (2007):

a) Content: elderly people must participate in the development of the subject and contents in order to take into account their needs (e.g., age, gender, education, learning types, professional experience) and the opening of new fields of activity and roles in society for the learner.

b) Methods/didactic: Methods must be developed for elderly learners; self-determination, i.e., learners influence methods and didactics; active participation of learners in the learning process (e.g., giving lectures, seminars); diagnosis of the level of learners' technical skills (preparatory courses and previous training materials for elderly); transparency of concept (aims, learning goals, learning times, success criteria); interactive communication (e.g. use of multi-level communication in learning platforms and real life meetings); consultation and support (both technical and administrative, conflict solving, moderation of subject matter and process); innovative aspects (inclusion of new methods and new technical developments).

c) Accessibility and participation: Acceptable cost (course, equipment and other materials); barrier freedom (in the design and layout of the technical tools, technical level does not exclude learners); good information measures (press work, public relations, information actions and campaigns). 
d) Continuity/sustainability: long-term use of the acquired skills and competencies; development of follow-up projects; influence of public policy-makers; publicity, dissemination and publication of results).

e) Quality control: Activities of R\&D /accompanying research, application of findings); evaluation (external and/or internal); documentation of success and constraints.

\section{Final remarks}

In a context of financial and economic crisis, improving digital inclusion can act as an enabler for citizens to actively participate in the economy and society of tomorrow. Greater e-Inclusion also generates systemic innovation, new business models, and new modalities for service delivery. By linking technology and service innovation to local entrepreneurship, e-Inclusion can become an engine for social enhancement and economic growth. Digital inclusion therefore can be considered a "structural investment" for innovation and economic growth.

The EU is increasingly seen as a reference in fostering innovation of social and health care systems through the use of ICT and by encouraging research and innovation through proper funding. Thanks to research on e-Accessibility, ICT in support of the elderly, or e-Health, key advances are generated for the benefit of weaker users, but also providing breakthroughs in consumer and electronics and mainstream technologies. The acquisition of computer literacy is becoming a necessity as a result of technological pressures changing ways people receive necessary services within our society. To function properly today and in the near future seniors will be required to enhance their ability to use computers on the same scale as they currently use telephones.

In addition, use of the Internet and e-mail can improve the quality of older adults' lives by providing a new connection to the outside world. As they grow older, many adults may become socially less active and may be separated by great distances from their family members. The Internet has the capability of creating a virtual "social network" (computer-mediated 
social network) that crosses generations and includes family members, friends, or other persons. In addition, older adults may retrieve a wide variety of helpful information (health, travel, and hobbies) from the Web. These characteristics of the Internet and e-mail could lead to enhanced social support and well-being of older adults.

A countervailing and important trend in ICT is user empowerment. Older users can be much better informed than ever before and thus increasingly take charge of their own health, fitness and independent living with the help of information on the Internet, television theme channels, and ICT-enabled daily life, personal health and fitness solutions.

\section{References}

Barnett, K., \& Adkins, B. (2004). Engaging with the future: Older learners see the potential of computers their lifestyle interests. Queensland: Queensland University of Technology.

Bernard, M., \& Phillips, J. (2000). The challenge of ageing in tomorrow's Britain. Ageing and Society, 20, 33-54.

Bli-Cohen, E., \& Litwin, H. (2005). Computer utilization in later-life: Characteristics and relationship to personal well-being. Gerontechjournal.net, 3(3), 138-148.

Chisnell, D., \& Redish, J. (2004). Designing Web Sites for Older Adults: Expert Review of Usability for Older Adults at 50 Web Sites. AARP.ORG.

Dickinson, A., \& Gregor., P. (2006). Computer use has no demonstrated impact on the wellbeing of older adults. International Journal of Human-Computer Studies, 64, 744-753.

European Commission (2006). The Ministerial Riga Declaration. Brussels: EU.

European Commission (2007). Ageing well in the Information Society: Action Plan on Information and Communication Technologies and Ageing. Brussels: EU.

Eurostat. (2007). Europe in figures - Eurostat yearbook 2006-07.

Harper, S. (2007). Is there design-for-all? Univ Access Inf Soc, 6, 111-113.

Hazzlewood, J. (2001). The TALANT: The third age learner accessing new technology. Proceedings of the $10^{\text {th }}$ National Conference of NCVER. Launceston: University of Tasmania.

ICT4T. (2006). Needs and Requirements Analysis. ILEU.

MacDonald, A. et al. (2007). Towards a design tool for visualizing the functional demand placed on older adults by everyday living tasks. Univ Access Inf Soc, 6, 137-144.

Malanowski, M., Özcivelek, R., \& Cabrera, M. (2008). Active Ageing and Independent Living Services: The role of Information and Communication Technology. Luxembourg: European Communities.

Millar, P., \& Falk, I. (2000). Seniors Online: Online literacy and learning by senior citizens in rural centres. Adult Literacy and Numeracy Australian Research Consortium - ALNARC. Melbourne: Victoria University. 
Morgan, R. (2005). Technology greets the age wave. The Gerontologist, 45(5), 704-710.

Negroponte, N. (1996). Being Digital. New York: Alfred A. Knopf.

Purdie, N., \& Boulton-Lewis, G. (2003). The learning needs of older adults. Educational Gerontology, 29, 129-149.

Selwyn, N. (2004). The information aged: A qualitative study of older adults' use of information and communications technology. Journal of Aging Studies, 18, 369-384.

Timmermann, S. (1998). The Role of Information Technology in Older Adult Learning. New Directions for Adult and Continuing Education, 77, 61-71.

West, D., Heath, D. (2009). Moving forward on digital inclusion: A framework for integrating research, policy and practice. Journal of Social Intervention: Theory and Practice, 18(2), $5-28$.

White, J., \& Weatherall, A. (2000). A grounded theory analysis of older adults and information technology. Educational Gerontology, 26, 371-386.

WHO (2002). Active ageing: A policy framework. World Health Organisation. 